\title{
Russian current versus high voltage current with isokinetic training on the quadriceps muscle strength and endurance
}

\author{
Bihter Akınoğlü ${ }^{1,2 * *}$, Tuğba Kocahan² \\ 'Department of Physiotherapy and Rehabilitation, Faculty of Health Sciences, Ankara Yıldırım Beyazıt University, Ankara, Turkey \\ ${ }^{2}$ Center of Athlete Training and Health Research, Department of Health Services, Sports General Directorship, The Ministry of Youth and Sports, Ankara, Turkey
}

Electrotherapy modalities are one of the increasing ways of muscle strength and endurance. However, it is not clear which electrotherapy modalities are more effective. The purpose of this study is to compare the effect of Russian current (RC) and high voltage pulsed current (HVPC) on the strength and endurance of the quadriceps muscle. The study was performed on 10 volleyball athletes. The participants' extremities were divided into two groups as RC and HVPC. Muscle strength and endurance levels were assessed by an isokinetic device. Isokinetic training and 20-min electrotherapy were given in each treatment session. This training program consisted of a total of 12 sessions, scheduled twice a week for 6 weeks. After training, knee extensor peak torque values and endurance ratios have increased in both groups, but it was determined that this increase was only significant in terms of the endurance ratio $(P<0.05)$. There was no significant difference between the muscle strength and the endurance ratio of the RC and HVPC groups $(P>0.05)$. RC or HVPC have no advantages over each other, and therefore it has been determined that both currents can be used in order to strengthen muscles and increase muscular endurance. Additional studies whose longer-term effects will investigate are needed.

Keywords: Electrotherapy, Exercise, Strengthening, Sport, Physiotherapy

\section{INTRODUCTION}

Volleyball is a complex sport that requires athletes to have high technical and tactical skills and athletic performance (Briner and Kacmar, 1997). Muscle strength and endurance are extremely important in many sport-specific activities such as jumping, changing direction, and improving athletic performance (Briner and Kacmar, 1997; Suchomel et al., 2016). The strength of knee muscles is particularly important in volleyball as it is directly related to the jumping ability and athletic performance (Hughes and Watkins, 2008; Sattler et al., 2016; Sharma et al., 2012). Strengthening and endurance trainings are routinely used to improve musculoskeletal performance both in rehabilitation and strengthening programs (Earl and Hoch, 2011; Jones and Carter, 2000; Jullien et al., 2008). Isokinetic trainings and neuromuscular elektrical stimulation
(NMES) are also frequently used in these as well as for rehabilitation programs (Brown and Whitehurst, 2003; Evetovich et al., 2001; Feiereisen et al., 1997; Ward and Shkuratova, 2002). Russian current (RC) and high voltage pulsed current (HVPC) are the preferred popular NMES methods for strengthening. These modalities are preferred because of their highest tolerance and minimum pain level (Feiereisen et al., 1997; Ward and Shkuratova, 2002).

It is not clear which electrotherapy modalities are more effective in increasing muscle strength and endurance in athletes. The purpose of this study was to compare the effects of muscular strength and muscular endurance in RC and HVPC, which will also be useful in isokinetic strengthening training in volleyball athletes. It is hypothesized that these two currents can be used to increase strength and muscular endurance, and that there will be no differ-
*Corresponding author: Bihter Akınoğlu (iD https://orcid.org/0000-0002-8214-7895 Department of Physiotherapy and Rehabilitation, Faculty of Health Sciences,

Ankara Yildırım Beyazıt University, Ankara, Turkey

E-mail: rgkardelen@yahoo.com

Received: April 3, 2020 / Accepted: April 30, 2020
This is an Open Access article distributed under the terms of the Creative Commons Attribution Non-Commercial License (https://creativecommons.org/licenses/by-nc/4.0/) which permits unrestricted non-commercial use, distribution, and reproduction in any medium, provided the original work is properly cited. 
ence between these currents on muscle strength and muscular endurance. This study will help us to determine which current with isokinetic training increases muscle strength and endurance more and a suggestion will be included as to which electrotherapy modality should be included in strengthening and endurance programs. Moreover, we will shed light on how muscle strength and muscular endurance, which affects sport performance, can be increased most effectively.

\section{MATERIALS AND METHODS}

\section{Ethical statement}

The study was approved by the local ethical committee (approve date 13.09.2017 and number: E-17-1353) and performed according to Helsinki declaration criteria; signed informed consent forms were collected from all subjects.

\section{Participants}

Our study was conducted in a Sports Health Education Research Center, where the study has started with the evaluation of 16 male volleyball athletes. Six of these athletes were later excluded from the study as two of of them did not meet the study criteria, two of them not attendance the regular training programme, one of them having tibial fracture and one of them not attendance to the study regularly. Thus, the study was completed with a total of 20 lower extremities on 10 male volleyball athletes. The lower extremities of the athletes were divided into two groups as RC and HVPC. While RC was applied to one of the lower extremities, the other extremity of the same athlete was applied HVPC. In order to eliminate the dominant effect, $\mathrm{RC}$ was randomly applied to the dominant limbs of half the athletes, while it was applied to the nondominant extremities of the other half. So totally 10 extremities which were applied to $\mathrm{RC}$ created the RC group and also 10 extremities which was applied to HVPC created the HVPC group.

\section{Inclusion and exclusion criteria}

The inclusion criteria were based on having the necessary physical fitness to perform the isokinetic evaluation and training processes, training 2-4 times a week, being a professional volleyball athlete for at least 3 years, playing in the second league and volunteering to participate in this study. The exclusion criteria included having any contraindication to the application of electrotherapy modalities, and having undergone hip, knee, ankle or lower back injuries and/or lower limb surgery within the past year.
Table 1. Physical characteristics of the participants during the experimental protocol $(n=10)$

\begin{tabular}{lcc}
\hline Variable & Median (IOR) & Mean \pm SD \\
\hline Age $(\mathrm{yr})$ & $15(14-16)$ & $15.50 \pm 1.08$ \\
Height $(\mathrm{cm})$ & $1.92(185-197)$ & $1.92 \pm 0.04$ \\
Body mass $(\mathrm{kg})$ & $76(69-85)$ & $75.91 \pm 19.75$ \\
Body mass index $\left(\mathrm{kg} / \mathrm{m}^{2}\right)$ & $20.55(17.16-23.4)$ & $20.55 \pm 5.16$ \\
\hline
\end{tabular}

IQR, interquartile range; SD, standard deviation.

This study was designed according to the Declaration of Helsinki and approved by the Ethics Committee of Education and Research Hospital Ethical Committee on Clinical Investigations on 13.09. 2017 with the decision no. E-17-1353. All the participants who agreed to participate in the study were informed about the purpose and the benefits of the study, and they were requested to sign a consent form prior to the study. Also, parental signed consent was also obtained from any participants under the age of 18 years (15.50 \pm 1.08 years). The descriptive characteristics of the participants including age, height, body mass, and dominant side (verbal confirmation of the dominant leg hitting the ball) were recorded. The demographic information of the participants included in the study is given in Table 1.

\section{Evaluation of isokinetic muscle strength}

The isokinetic testing was performed on an IsoMed 2000 machine (D.\& R. Ferstl GmbH, Hemau, Germany) and included measurements of knee extension peak torque. The test was performed by a physiotherapist following an electrotherapy procedure, and was performed in the same sequence on each participant before and after the training. The participants were asked to jog for 10 minutes at the $60 \%$ of the maximal heart rate to warm-up before starting the test. After warm-up, the participants were taken individually into the isokinetic device to be measured. The adjustment of the device was made according to the individual anthropometric structures of the participants. The angle of the joints was adjusted considering the joint's range of motion and the device's user's manual, and any movements other than the range of motion determined by the mechanical limits were prevented. Before each new angular velocity, three repetitive knee flexion and extension movements were performed at the same angular velocity so that the athlete could get familiarized with the motion at this angular velocity (familiarization). The isokinetic muscle strength was evaluated with 5 repetitions at $60 \%$ sec and 30 repetitions at $180 \%$ sec (Kocahan and Akınoğlu, 2018) The evaluations were performed bilaterally with the dominant side evaluated 
first, and the nondominant side 3 min later for half the athletes and vice versa for the other half. The peak torque was the peak value across the 5 collected trials then the 30 collected trials, measured in Newton meters $(\mathrm{Nm})$. In our study, only knee extensor muscles were considered in the evaluation of muscle strength and muscular endurance since the application of electrical stimulation was applied only to the knee extensor muscles, and the muscle fiber distribution of the knee extensor and flexor muscles was not similar.

The endurance of the quadriceps muscle was determined by the fatigue index (FI) and the total amount of work done for both legs before and after the training (Kannus, 1994; Wittstein et al., 2011). Fatigability was calculated as the percentage decline from the peak tork. The participants performed 30 maximal extensions at an isokinetic velocity of $180^{\circ} / \mathrm{sec}$. The FI was calculated as the percentage of force drop over the 30-repetition using the following formula: FI $(\%)=1-\{[($ initial 5 -last 5)/initial 5] $\times 100\}$. Higher values indicated lower values of fatigue resistance of associated muscle (Mohr et al., 1985). Since the FI is also a percentage and related to the starting and ending values of the participant, the total work done (joule) at $180^{\circ} / \mathrm{sec}$ angular velocity was also recorded in order to measure the muscular endurance (Binder-Macleod and Snyder-Mackler, 1993; Wittstein et al., 2011).

\section{Isokinetic strengthening training}

The preliminary preparation mentioned in the protocol for the evaluation of isokinetic muscle strength was also applied for isokinetic strengthening training. The participants were first asked to jog for $10 \mathrm{~min}$ and then to perform 1 set of 10 repetitive submaximal concentric knee flexion and extension movements at $60 \% \mathrm{sec}$ for warming before the strengthening training started. Strengthening training was performed with 3 sets of 10 repetitions at $60^{\circ} \%$ sec and 3 repetitions of 15 repetitions at $180^{\circ}$ /sec angular velocity. The isokinetic training was performed bilaterally. After isokinetic strengthening training, electrical stimulation was applied.

\section{Electrotherapy application}

The participants were subjected to NMES application after 20 min of isokinetic strength training in order to do some stretching and cool down. For both groups, the NMES surface carbon electrodes (Chattanooga, Mouguerre, France) were placed with a focus on the Quadriceps muscles; four electrodes $(6 \mathrm{~cm} \times 8 \mathrm{~cm})$ around the center of the quadriceps muscles on the motor points of the head of vastus medialis and rectus femoris. The intensity of NMES during the training was adjusted to $70 \%$ of the maximal individ- ual pain threshold (maximum tolerated intensity). The maximally tolerated intensity was verified separately for each pair of electrodes before each training session. The participants were sat in the starting position with a support under their $45^{\circ}$ flexed knee, before NMES application started and the voluntary quadriceps/hamstring muscle contraction takes place. Maximum intensity was adjusted to an intensity of $70 \%$ to enable dynamic movements (Wirtz et al., 2016). The lower extremities of the participants were divided into two groups as RC and HVPC. RC was applied to one of the lower extremities and to HVPC to the other. In order to eliminate the dominant effect, $\mathrm{RC}$ was randomly applied to the dominant limbs of half the participants, while it was applied to the nondominant extremities of the other half. The person who performed the data analysis was unaware to this randomization. A combined electrotherapy device (Intelect Neo, Chattanooga, Mouguerre, France) was used for the electrotherapy application. Impulse frequency of $\mathrm{RC}$ was set at $2,500 \mathrm{~Hz}, 50$ pulse/sec, pulse duration of $200 \mu \mathrm{sec}$ and with an on/off-ratio of 10/10 sec (Ward and Shkuratova, 2002). Impulse frequency of HVPC was set at 50 pulse/sec, pulse duration of $20 \mu \mathrm{sec}$ and with an on/off-ratio of 10/10 sec (Mohr et al., 1985). Quadriceps and hamstring muscles' contractions were synchronized for both NMES applications in on-time mode. So, the quadriceps muscle contracted as concentrically and eccentrically. Both NMES were applied for $20 \mathrm{~min}$. Two-channel electrotherapy was applied to the quadriceps muscle with a bipolar technique. The training intensity of each set was controlled by the Borg-scale and was set to > 16 (> "hard") (Wirtz et al., 2016).

The training program (isokinetic strengthening training +electrotherapy application) was completed with a total of 12 sessions scheduled 2 times per week over a duration of 6 weeks. Isokinetic muscle strength evaluation was performed before the training program and during the next session after the training program was completed (after 3 days).

\section{Statistical analysis}

Statistical analyses of the data obtained at the end of the study were performed using IBM SPSS Statistics ver. 20.0 (IBM Co., Armonk, NY, USA). The Shapiro-Wilks test was used to determine whether the data was appropriate for normal distribution, and it was determined that the data did not fit the normal distribution. The Mann-Whitney $U$-test was used to determine whether there was a significant difference between the baseline values of the extremities of the RC group and the HVPC group, and to compare the effectiveness of both currents. The strengthening effect of both currents was determined by pre and posttest values, 
Table 2. Baseline values of participants

\begin{tabular}{|c|c|c|c|}
\hline Variable & $\mathrm{RC}$ group $(\mathrm{n}=10)$ & HVPC group $(n=10)$ & $P$-value \\
\hline \multicolumn{4}{|l|}{ Knee extension } \\
\hline $60^{\circ} / \mathrm{sec} \mathrm{PT}(\mathrm{Nm})$ & $206.80(154.30-291.10)$ & $193.85(178.30-306.90)$ & 0.705 \\
\hline $180^{\circ} / \mathrm{sec} \mathrm{PT}(\mathrm{Nm})$ & $161.60(152.40-201.60)$ & $157.50(147.90-191.80)$ & 0.762 \\
\hline \multicolumn{4}{|c|}{ Quadriceps muscle $\left(180^{\circ} / \mathrm{sec}\right)$} \\
\hline $\begin{array}{l}\text { Muscular } \\
\quad \text { endurance (\%) }\end{array}$ & 72.02 (64.06-74.04) & $69.88(59.68-72.64)$ & 0.496 \\
\hline Total work (J) & $3,171.5(2,695-3,442)$ & $3,105(2,590-3,774)$ & 0.705 \\
\hline
\end{tabular}

Values are given as median (interquartile range).

RC, Russian current; HVPG, high voltage pulsed current; PT, peak torque; Nm, Newton meter; J, Joule.

${ }^{a}$ Mann-Whitney U-test.
Table 4. Comparison of RC and HVPC posttraining

\begin{tabular}{|c|c|c|c|}
\hline Variable & $R C$ group $(n=10)$ & HVPC group $(n=10)$ & $P$-value \\
\hline \multicolumn{4}{|l|}{ Knee extension } \\
\hline $60^{\circ} / \mathrm{sec} \mathrm{PT}(\mathrm{Nm})$ & $243.60(212.40-284.80)$ & $241.70(230.10-279.10)$ & 0.821 \\
\hline $180^{\circ} / \mathrm{sec} \mathrm{PT}(\mathrm{Nm})$ & $185.10(161.80-207.60)$ & $178.45(157.30-204.60)$ & 0.791 \\
\hline \multicolumn{4}{|c|}{ Quadriceps muscle (180\%/sec) } \\
\hline $\begin{array}{l}\text { Muscular } \\
\quad \text { endurance (\%) }\end{array}$ & $79.75(72.46-84.68)$ & $73.43(70.92-78.66)$ & 0.406 \\
\hline Total work (J) & $3,247.5(3,110-3,645)$ & $3,312.5(3,030-3,776)$ & 0.650 \\
\hline
\end{tabular}

Values are given as median and IOR 25-75.

RC, Russian current; HVPG, high voltage pulsed current; PT, peak torque; Nm, Newton meter; J, Joule.

${ }^{a}$ Mann-Whitney U-test.

Table 3. Effects of RC and HVPC on strength and muscular endurance

\begin{tabular}{|c|c|c|c|c|}
\hline Strength and muscular endurance & Group & Pretraining $(n=10)$ & Posttraining $(n=10)$ & $P$-value \\
\hline \multicolumn{5}{|l|}{ Knee extension PT (Nm) } \\
\hline \multirow[t]{2}{*}{$60^{\circ} / \mathrm{sec}$} & $\mathrm{RC}$ & $206.80(154.30-291.10)$ & 243.60 (212.40-284.80) & 0.059 \\
\hline & HVPC & $193.85(178.30-306.90)$ & $241.70(230.10-279.10)$ & 0.059 \\
\hline \multirow[t]{2}{*}{$180^{\circ} / \mathrm{sec}$} & $\mathrm{RC}$ & $161.60(152.40-201.60)$ & $185.10(161.80-207.60)$ & 0.074 \\
\hline & HVPC & 157.50 (147.90-191.80) & $178.45(157.30-204.60)$ & 0.074 \\
\hline \multicolumn{5}{|l|}{ Quadriceps muscle $\left(180^{\circ} / \mathrm{sec}\right)$} \\
\hline \multirow[t]{2}{*}{ Muscular endurance (\%) } & $\mathrm{RC}$ & $72.02(64.06-74.04)$ & $79.75(72.46-84.68)$ & $0.009^{*}$ \\
\hline & HVPC & $69.88(59.68-72.64)$ & $73.43(70.92-78.66)$ & $0.007^{*}$ \\
\hline \multirow[t]{2}{*}{ Total work (J) } & $\mathrm{RC}$ & $3,171.5(2,695-3,442)$ & $3,247.5(3,110-3,645)$ & $0.047^{*}$ \\
\hline & HVPC & $3,105(2,590-3,774)$ & $3,312.5(3,030-3,776)$ & $0.021^{*}$ \\
\hline
\end{tabular}

Values are given as median and interquartile range.

RC, Russian current; HVPG, high voltage pulsed current; PT, peak torque; Nm, Newton meter; J, Joule.

a'Wilcoxon Signed-Rank test. ${ }^{*} P<0.05$.

and Wilcoxon Signed Ranks test. Descriptive statistics were recorded by median and interquartile range. The significance level for all statistical analyses was considered as $P<0.05$.

\section{RESULTS}

Baseline values for the two groups are shown in Table 2. According to this table, there is no significant difference between quadriceps muscular strength, muscular endurance, and total work baseline values in RC and HVPC groups $(P>0.05)$ (Table 2). The effects of RC and HVPC on muscle strengthening, muscular endurance, and total work are shown in Table 3. According to this table, it was determined that peak torque values of knee extensors, quadriceps muscle endurance value, and total amount of work done increased in both groups at the end of the training. However, only the muscular endurance and the increase in total work value were found to be statistically significant $(P<0.05)$ (Table 3). Table 4 shows the comparison of the RC and HVPC group after the train- ing program. According to this table, there is no significant difference between muscular strength, endurance, and total work-related effects of the two currents $(P>0.05)$ (Table 4).

\section{DISCUSSION}

As a result of our study, to compare the efficiency of RC and HVPC; it was found that the effects of RC and HVPC on muscle strength and endurance were similar to each other. It was also found that both currents were effective in increasing muscular endurance.

Increasing muscle strength and endurance in all sports branches is the primary focus of training programs (Chen et al., 1994). Isokinetic muscle strength was also identified as one of the predictors of muscle performance in volleyball players (Croisier et al., 2007). In addition to the direct relationship with performance, muscle strength also determines the tendency to injury because of the muscle strength balance of the joints (Miller et al., 2006). Therefore, strengthening the right muscles is also at the center of the 
injury prevention programs. Isokinetic dynamometers are used for rehabilitation and training in order to both evaluate and increase muscle strength (Chen et al., 1994; Croisier et al., 2007; Eyigor et al., 2004; Miller et al., 2006). These devices allow for maximal contractions by allowing muscle function to be used at full speed over the entire range of joint movements. This helps to take efficient measurements and strengthening of the muscles (Chen et al., 1994; Croisier et al., 2007; Eyigor et al., 2004). In addition, electrotherapy modalities such as RC and HVPC are frequently used for strengthening muscles (Holcomb et al., 2007; Mohr et al., 1985; Ward and Shkuratova, 2002; Wirtz et al., 2016). However, as we know, no studies are available in which it is suggested that electrotherapy modalities with isokinetic strengthening training will further strengthen the muscle and increase the muscular endurance more.

As a result of our study, it was determined that RC and HVPC associated with isokinetic strengthening training were effective in increasing muscle strength. Also, the strength of the knee extensors has increased at both angular velocities $(60-180 \%$ sec) for which evaluation and training were performed. But it was determined that there was no superiority between the two currents in terms of strengthening. Our hypothesis was also in this direction at the beginning of our study. The RC, as one of the currents included in our study, is very popular despite the limited number of studies and findings examining its effectiveness (Hudlická et al., 1982). HVPC is a versatile current type, which is used for cases such as injury healing, edema control, pain management as well as strengthening. Therefore, the tolerance of athletes to this current is better compared to the RC (Holcomb et al., 2007). Our study has also shown that the effects of RC and HVPC on muscle strength at 60 and $180^{\circ} / \mathrm{sec}$ angular velocity are similar to each other.

Muscular endurance is not an inherent physical quality, but rather a quality of muscle that is semantically the opposite of fatigue (Kannus, 1994; Sapega, 1990). Muscular endurance has been evaluated in many studies using fatigue indices in many different ways (Pincivero et al., 2003; Wittstein et al., 2011). Total work (unit= joules, $\mathrm{J}$ ) is the sum of work performed in all test repetitions (Wittstein et al., 2011). Total work during all repetitions has also been used as methods of quantifying muscle endurance (Burdett and Vanswearingen, 1987; Kannus et al., 1992; Wittstein et al., 2011). In our study, muscular fatigue of knee extensors was evaluated by FI. At the same time, the total work done by the knee extensors was recorded during a total of 30 extension movements at an angular velocity of $180^{\circ} / \mathrm{sec}$. As a result of our study, it was determined that the fatigue of the quadriceps muscle has decreased and total work done by quadriceps muscle has increased. This result shows that the quadriceps muscle endurance has also increased, which is a very important finding. But, as we don't have a control group with a focus on only isokinetic strengthening training and that does not involve electrotherapy in our study, it is not possible to know exactly the reason of these increases in endurance.

The result of our study is interesting because we think muscle strength and muscular endurance are parallel to each other and the increase in quadriceps muscle strength does not become statistically significant. However, the increase in muscular endurance is statistically significant. There may be a few reasons for this. One of these reasons is; in our study, the training program was scheduled over a period of 6 weeks and with a total of 12 sessions, which may have been not enough to provide muscle strength gain. Because, it is suggested that more than six weeks of exercise training is needed to increase muscle strength (Natsume et al., 2018). Another reason can be due to the electrical stimulation of the skeletal muscle causing a series of events leading to rapid twitch type $2 \mathrm{~b}$ fibers; a conversion, which gives slow-twitch type 1 fiber properties (Ward, 2009; Ward and Shkuratova, 2002). These results may be coming out because these newly formed type 1 fibers are functionally resistant to fatigue, but have a low maximum contraction rate. Additional studies are needed with a control group for which the cause of this condition can be determined and that longer training programs with longer sessions are included and, long-term outcomes are followed.

Our study focused on increasing reliability of working with the preferred group. Participants were divided into groups in order to avoid differences between the baseline values and to prevent the dominant limb from being a confounding factor. When the RC was applied to the dominant extremity for half of the participants, $\mathrm{RC}$ was applied to the nondominant extremity to the other half. Thus, while HVPC was applied to the nondominant extremity of half of the participants, HVPC was applied to the dominant extremity of the other half.

We have not found any literature that was similar to ours. In fact, we noticed that the literature does not include many studies with non-injured participants in general, in which electrotherapy modalities are used to increase muscle strength and endurance. The limitations of our study are the absence of a control group with only isokinetic strengthening training without electrotherapy. Although the number of participants included in the study might seem not enough, 2 extremities of each athlete with a total of 20 cases were studied. At the same time, the fact that the athletes in 
our study were in the same team and participated in the same training program, removed the different possible effects of different training programs on muscle strength. Long-term studies are needed to investigate the functional effects of electrotherapy treatments and to determine the tolerance superiority of currents to each other.

In conclusion, $\mathrm{RC}$ and HVPC, which can be added to isokinetic strengthening exercises in volleyball athletes, have the same effect on muscle strength and endurance. Both currents can be used in order to increase muscular endurance. Therefore, coaches should plan a training with the electrotherapy modalities and isokinetic training especially if they want to improve the muscular endurance.

\section{CONFLICT OF INTEREST}

No potential conflict of interest relevant to this article was reported.

\section{REFERENCES}

Binder-Macleod SA, Snyder-Mackler L. Muscle fatigue: clinical implications for fatigue assessment and neuromuscular electrical stimulation. Phys Ther 1993;73:902-910.

Briner WW Jr, Kacmar L. Common injuries in volleyball. Mechanisms of injury, prevention and rehabilitation. Sports Med 1997;24:65-71.

Brown L, Whitehurst M. The effect of short-term isokinetic training on force and rate of velocity development. J Strength Cond Res 2003;17: 88-94.

Burdett R, Vanswearingen J. Reliability of lsokinetic Muscle Endurance Tests. J Orthop Sports Phys Ther 1987;8:484-488.

Chen WL, Su FC, Chou YL. Significance of acceleration period in a dynamic strength testing study. J Orthop Sports Phys Ther 1994;19:324330 .

Croisier JL, Malnati M, Reichard LB, Peretz C, Dvir Z. Quadriceps and hamstring isokinetic strength and electromyographic activity measured at different ranges of motion: a reproducibility study. J Electromyogr Kinesiol 2007;17:484-492.

Earl JE, Hoch AZ. A proximal strengthening program improves pain, function, and biomechanics in women with patellofemoral pain syndrome. Am J Sports Med 2011;39:154-163.

Evetovich TK, Housh TJ, Housh DJ, Johnson GO, Smith DB, Ebersole KT. The effect of concentric isokinetic strength training of the quadriceps femoris on electromyography and muscle strength in the trained and untrained limb. J Strength Cond Res 2001;15:439-445.
Eyigor S, Hepguler S, Capaci K. A comparison of muscle training methods in patients with knee osteoarthritis. Clin Rheumatol 2004;23:109-115.

Feiereisen P, Duchateau J, Hainaut K. Motor unit recruitment order during voluntary and electrically induced contractions in the tibialis anterior. Exp Brain Res 1997;114:117-123.

Holcomb W, Rubley MD, Girouard TJ. Effect of the simultaneous application of NMES and HVPC on knee extension torque. J Sport Rehabil 2007;16:307-318.

Hudlická O, Tyler KR, Srihari T, Heilig A, Pette D. The effect of different patterns of long-term stimulation on contractile properties and myosin light chains in rabbit fast muscles. Pflugers Arch 1982;393:164-170.

Hughes G, Watkins J. Lower limb coordination and stiffness during landing from volleyball block jumps. Res Sports Med 2008;16:138-154.

Jones AM, Carter $\mathrm{H}$. The effect of endurance training on parameters of aerobic fitness. Sports Med 2000;29:373-386.

Jullien H, Bisch C, Largouët N, Manouvrier C, Carling CJ, Amiard V. Does a short period of lower limb strength training improve performance in field-based tests of running and agility in young professional soccer players? J Strength Cond Res 2008;22:404-411.

Kannus P. Isokinetic evaluation of muscular performance: implications for muscle testing and rehabilitation. Int J Sports Med 1994;15 Suppl 1:S11-S18.

Kannus P, Cook L, Alosa D. Absolute and relative endurance parameters in isokinetic tests of muscular endurance. J Sports Rehabil 1992;1:2-12.

Kocahan T, Akınoğlu B. Determination of the relationship between core endurance and isokinetic muscle strength of elite athletes. J Exerc Rehabil 2018;14:413-418.

Miller LE, Pierson LM, Nickols-Richardson SM, Wootten DF, Selmon SE, Ramp WK, Herbert WG. Knee extensor and flexor torque development with concentric and eccentric isokinetic training. Res Q Exerc Sport 2006;77:58-63.

Mohr T, Carlson B, Sulentic C, Landry R. Comparison of isometric exercise and high volt galvanic stimulation on quadriceps femoris muscle strength. Phys Ther 1985;65:606-612.

Natsume T, Ozaki H, Kakigi R, Kobayashi H, Naito H. Effects of training intensity in electromyostimulation on human skeletal muscle. Eur J Appl Physiol 2018;118:1339-1347.

Pincivero DM, Gandaio CM, Ito Y. Gender-specific knee extensor torque, flexor torque, and muscle fatigue responses during maximal effort contractions. Eur J Appl Physiol 2003;89:134-141.

Sapega AA. Muscle performance evaluation in orthopaedic practice. J Bone Joint Surg Am 1990;72:1562-1574.

Sattler T, Sekulic D, Spasic M, et al. Isokinetic knee strength qualities as predictors of jumping performance in high-level volleyball athletes: multiple regression approach. J Sports Med Phys Fitness 2016;56:60-69. 
Sharma A, Geovinson SG, Singh Sandhu J. Effects of a nine-week core strengthening exercise program on vertical jump performances and static balance in volleyball players with trunk instability. J Sports Med Phys Fitness 2012;52:606-615.

Suchomel TJ, Nimphius S, Stone MH. The importance of muscular strength in athletic performance. Sports Med 2016;46:1419-1449.

Ward AR. Electrical stimulation using kilohertz-frequency alternating current. Phys Ther 2009;89:181-190.

Ward AR, Shkuratova N. Russian electrical stimulation: the early experi- ments. Phys Ther 2002;82:1019-1030.

Wirtz N, Zinner C, Doermann U, Kleinoeder H, Mester J. Effects of loaded squat exercise with and without application of superimposed EMS on physical performance. J Sports Sci Med 2016;15:26-33.

Wittstein JR, Queen R, Abbey A, Toth A, Moorman CT 3rd. Isokinetic strength, endurance, and subjective outcomes after biceps tenotomy versus tenodesis: a postoperative study. Am J Sports Med 2011;39: 857-865. 